\title{
Evaluation of the effects of laparoscopic adjustable gastric banding versus laparoscopic sleeve gastrectomy on weight loss
}

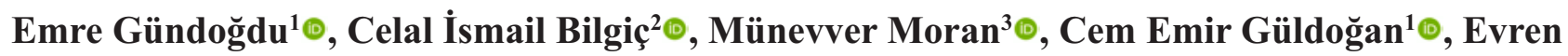 \\ Dilektaşlı ${ }^{4} \odot$, Mehmet Mahir Özmen ${ }^{1}$
}

${ }^{1}$ Department of Surgery, İstinye University School of Medicine, İstanbul, Turkey

${ }^{2}$ Department of Surgery, Umut Hospital, Ankara, Turkey

${ }^{3}$ Department of Surgery, Ankara Numune Training and Research Hospital, Ankara, Turkey

${ }^{4}$ Department of Surgery, University of Health Sciences, Bursa Yüksek Ihtisas Training and Research Hospital, Bursa, Turkey

\begin{abstract}
Objectives: Obesity has become one of the most serious and ever increasing health problems of our times. Diet, exercise and medical treatment have proven to be insufficient. Operations such as laparoscopic adjustable gastric banding (LAGB) and laparoscopic sleeve gastrectomy (LSG) have gained popularity. The purpose of this study is to conduct a retrospective comparative analysis of the clinical results gained from patients treated with LSG and LAGB due to morbid obesity.

Methods: The patients included in the study were selected among those who were diagnosed with morbid obesity and were operated with LAGB $(n=55)$ and LSG $(n=52)$ from May 2007 to December 2012. Both groups were compared in terms of the demographic characteristics, preoperative and postoperative conditions. Results: The groups were similar in terms of age, sex and BMI. In the 6th month, there was a notable loss of appetite in the LSG group patients compared to the LAGB patients $(69.2 \%$ vs. $23.6 \%, p<0.001)$. The rate of excess weight loss in the LAGB group was $23.93 \% \pm 7.98 \%$ and $31.7 \% \pm 7.49 \%$ in the LSG group in the postoperative 6 th months $(p=0.002)$. The rate of excess weight loss was $45.36 \% \pm 10.92 \%$ in the LAGB group and $60.3 \% \pm 9.81 \%$ in the LSG group in the postoperative 12 th months $(p<0.001)$.

Conclusions: When the two surgical operations for morbid obesity are compared LSG is found to be a more successful method in terms of body weight loss. Nevertheless, longer hospitalization can be associated with the technically more complicated nature of the operation and the fact that it requires resection.

Keywords: Obesity, bariatric surgery, sleeve gastrectomy, laparoscopic adjustable gastric banding
\end{abstract}

$\mathrm{O}$ besity is a serious epidemic problem with increased clinical significance worldwide as it is associated with several comorbidities and account for more than 2.5 million deaths per year worldwide [13]. Although numerous nonsurgical options are available to treat obesity, surgical interventions have proven to be the most reliable and effective methods for achieving weight loss [4]. Laparoscopic adjustable gastric band (LAGB) and laparoscopic gastric bypass (LGB) are the most frequently performed surgical interventions. However, the long-term outcomes of gastric banding procedures are often unsatisfactory [5]. 
Laparoscopic sleeve gastrectomy (LSG) is a modification of the Magenstrasse and Mill procedure, and has been proposed as an alternative restrictive bariatric procedure to the most popular LAGB [5]. The purpose of this prospective clinical trial was to measure and compare perioperative clinical and weight-loss outcomes between LSG and LAGB for the treatment of obesity.

\section{METHODS}

\section{Study Design}

This study was approved by the Scientific Research Evaluation Committee at Ankara Numune Training and Research Hospital. Morbidly obese patients who underwent LAGB or LSG between May 2007 and December 2012 at Ankara Numune Training and Research Hospital were enrolled in the study. Patients who underwent other surgical techniques to treat morbid obesity or re-do surgery were excluded from the study. The decision to undergo surgery in individual patients was based on the National Heart Lung and Blood Institute criteria, which stipulate the necessity of surgical intervention. Patients were interviewed before surgery, the expectations of the patients and physicians were recorded and a joint decision was taken regarding the surgical technique to be used. The patients were assessed by a dietician and received dietary guidance tailored to their individual characteristics to help maintain their target weight loss before surgery. In the pre-surgical period, respiratory exercise and prophylactic anti-thromboembolic drugs were started to minimize lung disorders or thromboembolism. The medical history of each patient was carefully reviewed before the procedure, and a physical examination was performed. After completing blood tests and radiological imaging in the pre-surgical period, the subjects underwent routine consultations in internal medicine, thoracic disease, endocrinology, dietetic, and psychiatric units as part of the multidisciplinary approach. Patients were given anti-thromboembolic prophylaxis before and after surgery till they discharged.

Patients in the LAGB group returned to the clinic every month for any necessary manipulation of their bands. Weight loss and body mass index (BMI) were regularly measured at each outpatient visit. Patients in the LAGB and LSG group were scheduled at 6 and 12 months after surgery to assess medical history, measure height and weight, and conduct basic biochemical tests. At the 6th-month visit, patients were also asked about any changes in appetite. The loss of excess weight was measured as a percentage of the patient's ideal weight determined before surgery. Excess weight was taken as the weight in kilograms above the weight at a BMI of $25 \mathrm{~kg} / \mathrm{m} 2$.

\section{Interventions}

All surgical procedures were performed by one of the authors (MMO) as primary surgeon at Ankara Numune Training and Research Hospital.

\section{LSG}

was performed using a four-ports approach. The gastrocolic ligament was divided by a vessel sealer device (LigaSure Vessel Sealing SystemTM; Valleylab, Boulder, CO, USA). The greater curvature of the stomach and the fundus were mobilized. Sleeve gastrectomy was performed by multiple applications of a $60 \mathrm{~mm}$ stapler (Echelon 60 Endopath Stapler and Cutter; Ethicon Endo-Surgery, Cincinnati, OH, USA or EndoGIA $60 \mathrm{~mm}$, Covidien, NewHaven, CTi USA) with staple-line reinforcement (Seamguard, Bioabsorbable Staple Line Reinforcement; W.L. Gore and Associates Inc. Flagstaff, AZ, USA), which extended 4-6 cm from the pylorus toward the angle of His. Intraoperative gastroscopy was performed to evaluate the integrity of the staple line and to perform an air-leak test. The resected stomach was removed through an extended trocar located at the left upper quadrant.

\section{LAGB}

LAGB was performed with four abdominal ports. A retro-gastric window was bluntly created using the pars flaccida technique. An adjustable gastric band (Soft Gastric Band Premium; A.M.I. GmbH, Feldkirch, Vorarlberg, Austria) was primed on the back table with approximately $3 \mathrm{~mL}$ of saline solution. The band was then inserted into the abdomen, placed below the gastroesophageal junction creating a small pouch and buckled in place. Three anterior nonabsorbable interrupted gastro-gastric stitches were 
placed to secure the band in place. The band tubing was connected to the access port, which was implanted subcutaneously and secured to the rectus abdominis fascia with interrupted, non-absorbable sutures.

\section{Statistical Analysis}

Data are expressed as the mean \pm standard deviation. The proportions of males/females were compared between the two groups using Pearson's $\chi 2$ test. The percent of excess weight lost at 6 and 12 months was compared using the Mann-Whitney U test. Other continuous variables were compared using Student's t test. Results with p-value of $\leq 0.05$ were considered statistically significant. Correlation analyses were performed using Pearson's correlation test. All analyses were performed using SPSS software version 17.0 (SPSS Inc., Chicago, IL, USA).

\section{RESULTS}

A total of 107 matched patients were included in the study, of which 55 underwent LAGB and 52 underwent LSG. There were $83(77.6 \%)$ females and $24(22.4 \%)$ males. The mean age of the patients was 35.83 years (range; 19-61). The mean body weight, BMI, and ideal body weight before surgery were $127.62(91-200) \mathrm{kg}, 46.4(34.2-64.1) \mathrm{kg} / \mathrm{m}^{2}$, and 61.7 (43.2-89.8) kg, respectively.

Table 1 compares the clinical characteristics, including proportions of patients with comorbidities, between the groups of patients. Of 55 patients who underwent LAGB, $40(72.7 \%)$ were females and 15 $(27.2 \%)$ were males. Their mean age was 36 (19-60) years. The mean body weight, BMI, and ideal body weight were $126.1 \mathrm{~kg}$ (91-174), $44.96 \pm 6.6 \mathrm{~kg} / \mathrm{m}^{2}$, and $61.2 \pm 12.1 \mathrm{~kg}$. Comorbidities included diabetes

Table 1. Comparison the clinical characteristics, including proportions of patients with comorbidities in both groups

\begin{tabular}{|c|c|c|c|}
\hline & $\begin{array}{c}\text { LAGB } \\
(n=55)\end{array}$ & $\begin{array}{c}\text { LSG } \\
(n=52)\end{array}$ & $p$ value \\
\hline $\operatorname{Sex}(F / M)$ & $40 / 15$ & $43 / 9$ & 0.812 \\
\hline Age (years) & $39(19-60)$ & $37(20-61)$ & 0.594 \\
\hline Weight (kg) & $126.1(91-174)$ & $134.6(105-200)$ & 0.182 \\
\hline BMI $\left(\mathrm{kg} / \mathrm{m}^{2}\right)$ & $44.96 \pm 6.6$ & $51.32 \pm 3.2$ & 0.720 \\
\hline Ideal weight (kg) & $61.2 \pm 12.1$ & $61.23 \pm 4.6$ & 0.910 \\
\hline \multicolumn{4}{|l|}{ Comorbidities } \\
\hline $\mathrm{DM}$ & $11(20 \%)$ & $4(7.7 \%)$ & \\
\hline $\mathrm{HT}$ & $11(20 \%)$ & $3(5.8 \%)$ & \\
\hline OSAS & $4(7.2 \%)$ & - & \\
\hline Gallbladder stones & $3(5.4 \%)$ & $1(1.9 \%)$ & \\
\hline Coronary diseases & $1(1.8 \%)$ & - & \\
\hline $\mathrm{OA}$ & $1(1.8 \%)$ & - & \\
\hline
\end{tabular}

LAGB = Laparoscopic adjustable gastric banding, BMI = Body mass index, LSG = Laparoscopic sleeve gastrectomy, DM = Diabetes Mellitus, HT = Hypertension, OSAS = Obstructive sleep apnea syndrome, OA = Oral antidiabetic, $\mathrm{F}=$ Female, $\mathrm{M}=$ Male 
mellitus in $11(20 \%)$ patients, hypertension in 11 $(20 \%)$ patients, obstructive sleep apnea syndrome in $4(7.2 \%)$ patients, gallbladder stones in $3(5.4 \%)$ patients, coronary artery disease in $1(1.8 \%)$ patient, osteoarthritis in $1(1.8 \%)$ patient, and gallbladder polyp in $1(1.8 \%)$ patient.

Of 52 patients who underwent LSG, $43(82.7 \%)$ were femals and $9(17.3 \%)$ were males. Their mean age was 37 (20-61) years. The mean body weight, BMI, and ideal body weight before surgery were 134.6 $(105-200) \mathrm{kg}, 51.32 \pm 3.2 \mathrm{~kg} / \mathrm{m}^{2}$, and $61.23 \pm 4.6 \mathrm{~kg}$. Comorbidities in this group included diabetes mellitus in $4(7.7 \%)$ patients, hypertension in $3(5.8 \%)$ patients, and gallbladder stones in $1(1.9 \%)$ patient.

Statistical analyses revealed that age $(p=0.594)$, sex distribution $(p=0.812)$, ideal weight $(p=0.91)$ and pre-surgical body weight $(p=0.182)$ were not significantly different between the two groups. Although body mass was greater in the LSG group than in the LAGB group, this difference was not statistically significant $(p=0.72)$.
All procedures in both groups were completed laparoscopically and there were no intraoperatively surgical complications. All four patients whose gallbladder stones were detected before surgery underwent laparoscopic cholecystectomy in the same session. No deaths were reported in either of the groups over the 1-year follow up. The mean hospital stay was 2.8 days (1-25) in the LAGB group and 6.2 days (4-11) in the LSG group. The mean hospital stay was therefore significantly longer in the LSG group than in the LAGB group $(p<0.001)$. One patient in the LAGB group developed acute necrotizing pancreatitis five days after surgery. The patient was discharged with appropriate monitoring and treatment. Other complications in the LAGB group included atelectasia, port infection, and intraabdominal infection, which occurred in three, two, and one patient, respectively. Therefore, the early morbidity rate in the LAGB group was $12.7 \%$. In the LSG group, atelectasia, wound site infection, and hemorrhage from the staple line occurred in three, one, and one patients,

Table 2. Comparison the changes in the study outcomes between the two groups

\begin{tabular}{|c|c|c|c|}
\hline & LAGB & LSG & $p$ value \\
\hline Weigt Loss in $6^{\text {th }}$ month $(\mathrm{kg})$ & $15 \pm 5.19$ & $24.79 \pm 8.91$ & 0.001 \\
\hline EWL in $6^{\text {th }}$ month $(\%)$ & $23.93 \pm 7.98$ & $31.7 \pm 7.49$ & 0.002 \\
\hline Loss of Appetite in $6^{\text {th }}$ month & $13(23.6 \%)$ & $36(69.2 \%)$ & $<0.001$ \\
\hline Weigt Loss in $12^{\text {th }}$ month $(\mathrm{kg})$ & $28.5 \pm 10.92$ & $41 \pm 14.44 \mathrm{~kg}$ & $<0.001$ \\
\hline EWL in $12^{\text {th }}$ month $(\%)$ & $45.36 \pm 10.92$ & $60.3 \% \pm 9.81 \%$ & $<0.001$ \\
\hline Lenght of stay (days) & $2.8(1-25)$ day & $6.2(4-11)$ day & $<0.001$ \\
\hline Early Complications & $7(12.7 \%)$ & $5(9.6 \%)$ & 0.139 \\
\hline Pancreatitis & 1 & - & \\
\hline Atelectesia & 3 & 3 & \\
\hline Port infection & 2 & - & \\
\hline Abdominal infection & 1 & - & \\
\hline Hemorragia & - & 1 & \\
\hline Wound site infection & - & 1 & \\
\hline
\end{tabular}

LAGB = Laparoscopic adjustable gastric banding, EWL = Excess weight loss, LSG = Laparoscopic sleeve gastrectomy 
respectively. The patient with hemorrhage was treated conservatively. The early morbidity rate in the LSG group was $9.6 \%$. Although the early morbidity rate was higher in the LAGB group than in the LSG group, the difference between the two groups was not statistically significant $(p=0.139)$.

In the long term, adjustable gastric band was removed from $11(20 \%)$ patients. The reason for band removal was band intolerance (intractable vomiting, pain, and inability to comply with diet) in $3(27.2 \%)$ patients, insufficient weight loss in $4(36.4 \%)$ patients, and band complications (slippage, erosion, leak or disconnection) in four (36.4\%) patients.

Table 2 compares the changes in the study outcomes between the two groups of patients. The mean weight loss at 6 months after surgery was $15 \pm$ $5.19 \mathrm{~kg}$ and $24.79 \pm 8.91 \mathrm{~kg}$ in the LAGB and LSG groups, respectively. The percent of excess weight lost at 6 months after surgery was $23.93 \% \pm 7.98 \%$ and $31.7 \% \pm 7.49 \%$ in the LAGB and LSG groups, respectively. The mean weight loss $(P=0.001)$ and the percent of excess weight lost $(p=0.002)$ at 6 months were both significantly greater in the LSG group than in the LAGB group. Overall, 13 (23.6\%) patients in the LAGB group and $36(69.2 \%)$ patients in the LSG group reported a decrease in appetite at 6 months after surgery. The proportion of patients who reported a decrease in appetite was significantly greater in the LSG group than in the LAGB group ( $p$ $<0.001)$.

At 12 months after surgery, the mean weight loss was $28.5 \pm 10.92 \mathrm{~kg}$ and $41 \pm 14.44 \mathrm{~kg}$ in the LAGB and LSG groups, respectively. The percent of excess weight lost was $45.36 \% \pm 10.92 \%$ and $60.3 \% \pm 9.81 \%$ in the LAGB and LSG groups, respectively. The mean weight loss $(p<0.001)$ and percent loss of excess weight $(p<0.001)$ were significantly greater in the LSG group than in the LABG group (see Table 2).

\section{DISCUSSION}

LAGB is increasingly being performed because of its relatively low complexity and adjustability, as well as its low perioperative morbidity $(1 \%-5 \%)$ and mortality $(0 \%-0.05 \%)$ rates $[6,7]$. Furthermore, the procedure is considered reversible as the stomach regains its normal anatomy after removing the band
[8]. However, there are some limitations to LAGB. In particular, band-related complications such as esophageal dilatation, food intolerance, gastric necrosis, band slippage, band dilation, and pouch dilation occur in $15 \%-58 \%$ of patients undergoing LAGB [8-10]. Furthermore, many patients experience inadequate weight loss or weight regain after an initial period of weight loss. Inadequate weight loss and weight regain were indications for repeated surgery in $27 \%-100 \%$ of patients who underwent LAGB [11]. LSG was initially introduced as the first step of the duodenal switch procedure but it is increasingly being offered as a primary independent bariatric operation [12].

In the present study, the percent of excess weight lost at 12 months after surgery was $60.3 \%$ for LSG and $45.36 \%$ for LAGB. Our data are consistent with the results of prospective randomized clinical trials by Himpens et al. [13] and Varela [5] that compared gastric banding with sleeve gastrectomy. In both trials, sleeve gastrectomy was associated with superior weight loss but with a greater number of complications compared with gastric banding. Likewise, in a metaanalysis that included 940 patients, Shi et al. [1] reported that the percent of excess weight lost at 1 year was $59.8 \%$ for LSG and $37.8 \%$ for LABG. According to these prior reports, LSG is effective in the short term and may offer some advantages over existing options, namely LAGB and laparoscopic Roux-en-Y gastric banding [1]. Based on these prior reports and our present findings, we consider that LSG is more effective than LAGB for achieving weight loss.

There is substantial evidence showing that gastric restriction is the main mechanism for weight loss after LAGB [14]. LSG was originally thought to be a purely mechanically restrictive procedure [15]. However, there is evidence that other factors might contribute to weight loss after LSG. In particular, LSG seems to increase gastric emptying [16, 17]. The levels of ghrelin, an orexigenic peptide that stimulates appetite, were reported to decline, causing early satiety [18]. In a systematic review, Anderson et al. [19] reported that LSG has significant effects on ghrelin levels at 3, 6, and 12 months, leading to considerable reductions in its circulating levels after LSG procedure. In our study, a significantly greater proportion of patients in the LSG group reported a reduced appetite at 6 months after surgery compared with patients in the LAGB 
group. This finding, although we didn't measure ghrelin levels, may be due to a reduction in ghrelin levels in LSG group.

Although LAGB is an appealing bariatric procedure because of it has minimal mortality and almost negligible perioperative complication rates [2022], and also it is reversible, allowing a "return to normal" in cases of intolerance [23, 24], unfortunately, LAGB is fraught with a high rate of long-term complications, leading to a large subset of patients who require reoperations, replacements, reconnections, and explanations for various reasons [9, 20, 25]. Mittermair et al. [26] have shown that $50.4 \%$ complications occurred in their series. Tolonen et al. [20] have shown that major late complications (including band erosions, slippage, leakage leading to major reoperation) occurred in $24.4 \%$ of patients. Also Khan et al. [27] have emphasized that LAGB is associated with a cumulative failure and complication rate of up to $30 \%$. In our study the band was removed from $11(20 \%)$ patients.

In a review of randomized controlled trials, Chakravarty et al. [28] reported that LAGB is associated with shorter length of hospital stay than other bariatric procedures. Likewise, Shi et al. [1] reported that the mean hospital stay was 4.4 days for LSG and 1.7 days for LAGB. Similarly, the length of hospital stay was significantly shorter in the LAGB group than in the LSG group in our study. However, this is not surprising considering that LSG is a more complicated procedure than LAGB.

\section{CONCLUSION}

Follow-up in our study is comparably shorter than other studies. Therefore complications related to the band and the rate of band removal might be higher than we found with a longer follow up. Also, rate of the excess weight loss might be lower in LSG group with longer follow up. However, with the current data we conclude that LSG was more successful in terms of the magnitude of weight loss after surgery and the loss of appetite.

\section{Conflict of interest}

The author disclosed no conflict of interest during the preparation or publication of this manuscript.

\section{REFERENCES}

1. Shi X, Karmali S, Sharma AM, Birch DW. A review of laparoscopic sleeve gastrectomy for morbid obesity. Obes Surg 2010;20:1171-7.

2. Padwal RS, Pajewski NM, Allison DB, Sharma AM. Using the Edmonton obesity staging system to predict mortality in a population-representative cohort of people with overweight and obesity. CMAJ 2011;183:E1059-66.

3. Li Z, Bowerman S, Heber D. Health ramifications of the obesity epidemic. Surg Clin North Am 2005;85:681-701.

4. Samuel I, Mason EE, Renquist KE, Huang YH, Zimmerman MB, Jamal M. Bariatric surgery trends: an 18-year report from the International Bariatric Surgery Registry. Am J Surg 2006;192:657-62.

5. Varela JE. Laparoscopic sleeve gastrectomy versus laparoscopic adjustable gastric banding for the treatment severe obesity in high risk patients. JSLS 2011;15:486-91.

6. Chapman AE, Kiroff G, Game P, Foster B, O'Brien P, Ham J, et al. Laparoscopic adjustable gastric banding in the treatment of obesity: a systematic literature review. Surgery 2004;135:32651 .

7. Boza C, Gamboa C, Perez G, Crovari F, Escalona A, Pimentel F, et al. Laparoscopic adjustable gastric banding LAGB: surgical results and 5-year follow-up. Surg Endosc 2011;25:292-7.

8. Hii MW, Lake AC, Kenfield C, Hopkins GH. Laparoscopic conversion of failed gastric banding to Roux-en-Y gastric bypass. Short-term Follow-up and technical considerations. Obes Surg 2012;22:1022-8.

9. Suter M, Calmes JM, Paroz A, Giusti V. A 10-year experience with laparoscopic gastric banding for morbid obesity: high longterm complication and failure rates. Obes Surg 2006;16:829-35. 10. Chevallier JM, Zinzindohoue F, Douard R, Blanche JP, Berta JL, Altman JJ, et al. Complications after laparoscopic adjustable gastric banding for morbid obesity: experience with 1,000 patients over 7 years. Obes Surg 2004;14:407-14.

11. Langer FB, Bohdjalian A, Shakeri-Manesch S, Felberbauer FX, Ludvik B, Zacherl J, et al. Inadequate weight loss vs secondary weight regain: laparoscopic conversion from gastric banding to Roux-en-Y gastric bypass. Obes Surg 2008;18:13816.

12. Deitel M, Crosby RD, Gagner M. The first international consensus summit for sleeve gastrectomy. Obes Surg 2008; 18:487-96.

13. Himpens J, Dapri G, Cadiere GB. A prospective randomized study between laparoscopic gastric banding and laparoscopic isolated sleeve gastrectomy: results after 1 and 3 years. Obes Surg 2006;16:1450-6.

14. Burton PR, Brown WA. The mechanism of weight loss with laparoscopic adjustable gastric banding: induction of satiety not restriction. Int J Obes (Lond) 2011;35 Suppl 3:S26-30.

15. Yehoshua RT, Eidelman LA, Stein M, Fichman S, Mazor A, Chen J, et al. Laparoscopic sleeve gastrectomy--volume and pressure assessment. Obes Surg 2008;18:1083-8.

16. Melissas J, Koukouraki S, Askoxylakis J, Askoxylakis I, Metaxari M, Dimitriadis E, et al. Sleeve gastrectomy - a "food limiting” operation. Obes Surg 2008;18:1251-6. 
17. Gagner M. Faster gastric emptying after laparoscopic sleeve gastrectomy. Obes Surg 2010;20:964-5.

18. Ashrafian H, le Roux CW. Metabolic surgery and gut hormones - a review of bariatric entero-humoral modulation. Physiol Behav 2009;97:620-31.

19. Anderson B, Switzer NJ, Almamar A, Shi X, Birch DW, Karmali S. The impact of laparoscopic sleeve gastrectomy on plasma ghrelin levels: a systematic review. Obes Surg 2013;23:1476-80.

20. Tolonen P, Victorzon M, Makela J. 11-year experience with laparoscopic adjustable gastric banding for morbid obesity - what happened to the first 123 patients? Obes Surg 2008;18:251-5.

21. Ren CJ, Weiner M, Allen JW. Favorable early results of gastric banding for morbid obesity: the American experience. Surg Endosc 2004;18:543-6.

22. O'Brien PE, Dixon JB, Brown W, Schachter LM, Chapman L, Burn AJ, et al. The laparoscopic adjustable gastric band (LapBand): a prospective study of medium-term effects on weight, health and quality of life. Obes Surg 2002;12:652-60.

23. Lanthaler M, Strasser S, Aigner F, Margreiter R, Nehoda H.
Weight loss and quality of life after gastric band removal or deflation. Obes Surg 2009;19:1401-8.

24. Dargent J. Isolated food intolerance after adjustable gastric banding: a major cause of long-term band removal. Obesity Surg 2008; 18:829-32.

25. Martin LF, Smits GJ, Greenstein RJ. Treating morbid obesity with laparoscopic adjustable gastric banding. Am J Surg 2007; 194:333-43.

26. Mittermair RP, Obermüller S, Perathoner A, Sieb M, Aigner F, Margreiter R. Results and complications after Swedish adjustable gastric banding-10 years' experience. Obes Surg 2009;19:1636-41.

27. Khan OA, Mansour S, Irukulla S, Reddy KM, Vasilikostas G, Wan AC. Sleeve gastrectomy for gastric band failures - a prospective study. Int J Surg 2013;11:407-9.

28. Chakravarty PD, McLaughlin E, Whittaker D, Byrne E, Cowan E, Xu K, et al. Comparison of laparoscopic adjustable gastric banding (LAGB) with other bariatric procedures; a systematic review of the randomized controlled trials. Surgeon 2012;10:172-82. 